\title{
Rancang Bangun Sistem Informasi Penerimaan Peserta Didik Baru Berbasis Website Dengan Metode Spiral
}

\author{
Kartika Puspita ${ }^{1}$, Yuris Alkhalifi ${ }^{2}$, Hasan Basri ${ }^{3}$ \\ ${ }^{1}$ Universitas Bina Sarana Informatika \\ e-mail: kartik12180567@bsi.ac.id \\ ${ }^{2}$ Universitas Bina Sarana Informatika \\ e-mail: yuris.yak@bsi.ac.id \\ ${ }^{3}$ Universitas Bina Sarana Informatika \\ e-mail: hasan.hhi@bsi.ac.id
}

\begin{abstract}
Abstrak - Penerimaan Peserta Didik Baru (PPDB) merupakan agenda tahunan setiap institusi atau institusi pendidikan dalam rangka menerima siswa baru di lingkungannya. Seringkali instansi atau lembaga tersebut sering mengalami kendala dalam pengelolaan administrasi siswa baru, salah satunya Raudhatul Athfal Sirojul Falah. Permasalahan yang terjadi pada urusan administrasi diantaranya masih seringnya masalah penginputan data siswa baru dan tidak tertata sehingga data tersebut menjadi sulit untuk ditemukan. Maka dengan itu pada penelitian ini akan dibuat sistem informasi PPDB untuk mengatasi masalah tersebut. Sistem informasi yang akan dibuat berupa desain UML (Unified Modeling Language), ERD (Entity Relationship Diagram) dan LRS (Logical Record Structure) serta website dengan bahasa pemrograman PHP, framework codeigniter dan bootstrap library. Hasil dari penelitian ini adalah dibangunnya sistem informasi PPDB di RA Sirojul Falah berupa website menggunakan metode spiral dengan harapan dapat membantu panitia PPDB RA Sirojul Falah dalam mengelola data mahasiswa baru secara efektif dan efisien.
\end{abstract}

Kata Kunci: Sistem Informasi, Metode Spiral, CodeIgniter, PPDB, RA Sirojul Falah Karawang.

\begin{abstract}
Penerimaan Peserta Didik Baru (PPDB) is an annual agenda for every institution or educational institution in order to accept new students in its environment. Often these agencies or institutions often experience problems in managing the administration of new students, one of which is Raudhatul Athfal Sirojul Falah. The problems that occur in administrative matters include the frequent problems of inputting new student data and it is not organized so that the data becomes difficult to find. So that in this study a PPDB information system will be created to solve this problem. The information system that will be created is in the form of a UML (Unified Modeling Language) design, ERD (Entity Relationship Diagram), and LRS (Logical Record Structure) as well as a website with the PHP programming language, CodeIgniter framework, and bootstrap library. The result of this research is the construction of a PPDB information system at RA Sirojul Falah in the form of a website using the spiral method with the hope of helping the PPDB RA Sirojul Falah committee in managing new student data effectively and efficiently.
\end{abstract}

Keywords: Information System, Spiral Method, CodeIgniter, PPDB, RA Sirojul Falah Karawang

\section{PENDAHULUAN}

Secara umum pengertian pendidikan adalah upaya sadar dan terencana untuk menciptakan suasana belajar dan proses pembelajaran, sehingga peserta didik dapat secara aktif mengembangkan potensinya, sehingga memiliki jiwa, penguasaan diri, kepribadian, kecerdasan, akhlak mulia dan diri sendiri, masyarakat, lingkungan dan negara (Haryati, 2017). Pendidikan dapat diperoleh dan dilaksanakan dimanapun di keluarga, masyarakat maupun lingkungan sekolah. Salah satu hal penting yang harus diperhatikan oleh negara adalah pendidikan. Untuk menjamin kelangsungan hidup bangsa hanya pendidikan yang paling penting dalam segala hal, karena pendidikan adalah wadah untuk meningkatkan dan mengembangkan kualitas sumber daya manusia, itu sebabnya pendidikan tidak terlepas dari kehidupan manusia sehingga menjadi semakin menarik perhatian.

Atas dasar itulah maka tujuan Raudhatul Athfal (RA) secara keseluruhan adalah membentuk anak Indonesia yang berdedikasi tinggi serta memiliki kualitas, yaitu anak yang berkembang sesuai dengan tingkat perkembangannya sendiri, sehingga siap untuk mengenyam pendidikan dasar dan membantu mereka mempersiapkan diri untuk persiapan studi (akademik) di sekolah. Raudhatul Athfal (RA) adalah pendidikan prasekolah dalam jalur pendidikan formal. Organisasi menyelenggarakan program pendidikan bercirikan islami bagi anak yang berusia 4 sampai 6 tahun. 
(Mesiono, 2017). RA juga merupakan bentuk pendidikan prasekolah yang mengembangkan keterampilan dasar. Raudhatul Athfal berperan penting dalam membantu anak membangun moralitas, nilai-nilai agama, emosi sosial, konsep diri, disiplin dan kemandirian, serta mengembangkan keterampilan fisik, bahasa, kognitif dan artistik.

Pelaksanaan pendidikan Raudhatul Athfal (RA) bertujuan untuk membekali anak dengan berbagai kebiasaan. Ini penting bagi anak-anak untuk beradaptasi dengan lingkungan dan tumbuh serta berkembang lebih jauh. Raudhatul Athfal Sirojul Falah Karawang merupakan forum pendidikan yang berperan serta dalam membina dan mendampingi anak agar mereka bisa bersosialisasi dan bermain sambil belajar. Untuk mendapatkan SDM yang berkualitas, diperlukan tahap penerimaan siswa baru RA.

Peserta Didik adalah anggota masyarakat yang berupaya mengembangkan potensinya serta proses pembelajaran tersedia melalui jalur, jenjang dan jenis pendidikan tertentu (Hasbullah, 2019). PPDB merupakan salah satu proses pendaftaran yang ada di instansi/lembaga. Yang tentunya PPDB harus melalui persyaratan yang telah ditentukan di sekolah tersebut. Namun semakin pesatnya perkembangan teknologi apalagi sekarang sedang pandemi COVID-19, belum lagi banyak orang tua yang sibuk dengan pekerjaannya sehingga tidak sempat pergi ke sekolah untuk mencari informasi dan mendaftarkan anakanaknya dengan tepat waktu. Seiring dengan semakin berkembangnya teknologi saat ini kebutuhan terhadap informasi sangat penting sehingga informasi dapat diakses kapanpun dan dimanapun asal terhubung dengan internet.

Website merupakan ringkasan halaman di domain atau subdomain, di dalam World Wide Web (WWW) di internet (Josi, 2017). Karena fungsinya situs website bisa menyajikan informasi dengan lengkap dan mudah untuk diakses oleh masyarakat. Pada institusi pendidikan, sistem informasi ini bertujuan untuk mempromosikan atau memberikan gambaran tentang institusi pendidikan, institusi administrasi dan fasilitas lainnya. RA Sirojul Falah Karawang merupakan salah satu Raudhatul Athfal yang paling diminati, sehingga sekolah ini banyak dipilih oleh calon orang tua siswa dan populer di masyarakat sekitar, namun demikian sistem penerimaan siswa baru sekolah tersebut masih menggunakan metode konvensional. Masalahnya, staff PPDB seringkali membutuhkan waktu lama untuk memasukkan data siswa ke dalam Microsoft Excel, dan staff PPDB sering melakukan kesalahan pada program Microsoft Excel saat melapor kepada kepala sekolah..

PPDB ini juga terdapat beberapa masalah antara lain banyak kendala, kekurangan pada pemrosesan maupun pengolahan data yang masih dilakukan secara manual sehingga membutuhkan waktu yang cukup lama, sehingga efisiensi pengolahan datanya belum tinggi. Untuk itu diperlukan suatu sistem informasi yang dapat membantu dalam proses PPDB (Najamudin et al., 2019). Dengan adanya PPDB berbasis sistem informasi maka data yang tersimpan akan jauh lebih aman, akurat serta menunjang segala kebutuhan. Proses mencari data siswa yang baru serta pengolahan data siswa bisa dilakukan lebih efektif dan efisien. Atas dasar identifikasi masalah yang telah dipaparkan diatas, maka rumusan masalah pada laporan ini adalah bagaimana membuat program PPDB pada Raudhatul Athfal Sirojul Falah untuk mempermudah petugas PPDB dalam mengelola operasional PPDB.

Penelitian sebelumnya dilakukan pembuatan sistem informasi PPDB berbasis website pada SMPN 1 Wanasari Brebes. Penelitian ini memiliki tujuan untuk membantu sekolah tersebut dalam menerapkan sistem dan manajemen data siswa yang lebih efisien. Sistem informasi dibangun dengan menggunakan (DAD) atau biasa disebut dengan Diagram Alir Data dan diterjemahkan kedalam bahasa pemrograman PHP \& MySQL untuk basis datanya (Ramdhan \& Wahyudi, 2019).

Penelitian lainnya dilakukan pembuatan sistem informasi PPDB berbasis website dan SMS Gateway pada SMKN 1 Rupat. Penelitian ini tujuannya untuk membantu kinerja tata usaha dalam melayani calon siswa baru yang akan mendaftar agar lebih efektif dan efisien. Sistem informasi ini dibangun dengan menggunakan DFD (Data Flow Diagram) serta diagram HIPO (Hierarchy Input Process Output) dan diterjemahkan kedalam bahasa pemrograman PHP \& MySQL untuk basis datanya (Suherni et al., 2017).

Sedangkan penelitian lainnya dilakukan pembuatan sistem informasi PPDB berbasis website pada SMA Budi Mulia Tangerang. Tujuan penelitian ini untuk mengetahui mekanisme prosedur sistem PPDB. Sistem informasi ini dirancang menggunakan metode UML, basis data yang dipakai untuk merancang sistem yaitu ERD, LRS \& Activity Diagram serta diterjemahkan kedalam bahasa pemrograman PHP \& MySQL (Aprilyani \& Syarifuddin, 2016).

Adapun dalam penelitian ini akan dilakukan pembuatan sistem informasi berbasis website pada Raudhatul Athfal Sirajul Falah Karawang dengan menggunakan metode spiral. Rancangan yang akan digunakan yakni UML berupa Usecase \& Activity Diagram, ERD, LRS dan aplikasi yang dibangun akan menggunakan PHP, MySQL, library Bootstrap \& Frameword Codeigniter. 


\section{METODOLOGI PENELITIAN}

Metode yang dipakai untuk membuat sistem informasi ini menggunakan metode spiral. Metode spiral adalah model proses perangkat lunak evolusioner yang menghubungkan sifat iteratif prototipe melalui aspek kontrol dan sistem dari model hasil linier. Model ini berpotensi untuk mengembangkan perangkat lunak versi lain dengan cepat. Dalam model spiral, perangkat lunak dikembangkan secara bertahap. Selama iterasi awal, rilis tambahan dapat berupa model kertas atau prototipe. Pada iterasi berikutnya, versi yang lebih lengkap dari sistem teknik diproduksi (Utomo \& Alfaridzi, 2018).

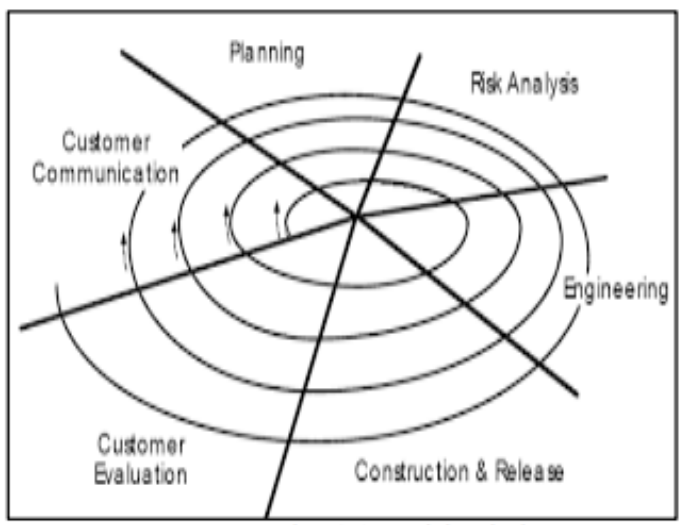

Sumber: (Wahyuni \& Cahyani, 2020)

Gambar 1. Metode Spiral

\section{Customer Communication}

Pada tahap ini dilakukan komunikasi antara pelanggan dengan permintaan yang diinginkan pelanggan, yaitu apa yang dibutuhkan dalam sistem. Seperti pengumpulan data berupa observasi dan wawancara, kebutuhan pengguna dan sistem,. Teknik pengumpulan data adalah suatu hal yang terpenting dalam penelitian, karena tujuan utama penelitian adalah untuk memperoleh data tanpa memahami teknologi pengumpulan data, sehingga tidak akan memperoleh data yang sesuai (Effendy \& Sunarsi, 2020).

Pada penelitian terdapat 2 teknik pengumpulan data yakni data primer dan data sekunder. Data primer merupakan data yang diperoleh dengan menggunakan wawancara, observasi, angket dan pertanyaan lisan lainnya (Alkhalifi et al., 2020). Sedangkan data yang bersumber dari sumber data lain atau data yang diperoleh dari subjek penelitian yaitu berupa dokumen merupakan data sekunder (Ermawati, 2019). Dalam penelitian ini digunakan teknik pengumpulan data primer sebagai sumber datanya.

a. Observasi

Observasi (Observation) merupakan teknik pengumpulan data dengan cara mengamati langsung objek penelitian dan menarik kesimpulan dari semua aktivitas objek tersebut (Sentosa, 2017). Sehingga semua informasi yang didapat bersifat akurat dan tepat (Basri et al., 2019).

b. Wawancara

Wawancara (Interview) adalah teknik penelitian yang menggunakan dialog langsung atau tidak langsung (tatap muka) atau melalui media tertentu antara pengunjung dan narasumber sebagai sumber data (Ahsanulkhaq, 2019).

\section{c. Studi Pustaka}

Studi pustaka (Library Research) adalah studi yang menggunakan berbagai bahan yang ada di perpustakaan (seperti dokumen, buku, majalah, cerita sejarah, dan lain-lain) untuk mengumpulkan informasi dan data penelitian (Abdi \& Purwoko, 2017).

\section{Planning}

Kegiatan perencanaan yang menetapkan tujuan yang ingin dicapai dan metode untuk mencapainya seperti menentukan waktu pengerjaan, sumber daya dan informasi lainnya yang dibutuhkan seperti spesifikasi hardware \& software yang digunakan.

\section{Risk Analysist}

Kegiatan analisis risiko ini dilakukan untuk menganalisa risiko teknologi dan teknis pengelolaan. Perancangan sistem menggunakan pemodelan berupa rancangan antarmuka, Unified Modelling Language (UML), Entity Relationship Diagram (ERD) serta Logical Record Structure (LRS). ERD merupakan diagram relasi entitas sebagai model penjelas relasi dalam database berdasarkan suatu pemahaman kata dari objek (Hasan, Nur \& Nurlelah, 2020). LRS merupakan model diagram ER yang mengikuti aturan pemodelan tertentu yang terkait dengan LRS (Ratnawati et al., 2018). UML merupakan bahasa spesifikasi standar yang digunakan untuk menggambarkan, menentukan dan membangun perangkat lunak. UML adalah metode pengembangan sistem berbasis objek serta alat yang mendukung pengembangan sistem (Hendini, 2016).

\section{Engineering}

Kegiatan yang diperlukan untuk membangun 1 atau lebih representasi dari aplikasi tersebut. Mungkin tidak ada pada tahap ini model proses yang juga menggunakan pendekatan berulang, namun hanya dilakukan pada model spiral saja. Jika pengguna (user) menemukan fungsi update atau memperbaiki error saat menggunakan sistem, maka maintenance akan dilakukan. Sistem informasi ini akan dibuat dengan PHP, framework Codeigniter dan library Bootstrap sebagai bahasa pemrograman. PHP (singkatan: hypertext preprocessor) adalah sebuah bahasa Pemrograman berbasis web. Oleh karena itu, PHP merupakan bahasa pemrograman biasanya digunakan untuk membuat aplikasi berbasis web (website, blog atau aplikasi web) (Christian et al., 2018). Bootstrap adalah paket aplikasi siap pakai untuk front-end situs web. Dengan kata lain, Bootstrap adalah template desain Web fungsional. Bootstrap dibuat untuk menyederhanakan proses desain web di semua tingkatan, dari pemula hingga pengguna berpengalaman. Pengetahuan dasar tentang HTML dan CSS, anda dapat menggunakan bootloader (Christian 
et al., 2018). Codeigniter adalah aplikasi kode dasar (open source) berupa framework dengan model MVC (model, view, controller), digunakan untuk membuat sebuah website dinamis (Cahyati \& Murti, 2018).

\section{Construction \& Release}

Aktivitas yang dibutuhkan untuk pembangunan perangkat lunak, pengujian, instalasi dan penyediaan pengguna atau dukungan pelanggan, seperti pelatihan penggunaan perangkat lunak dan dokumen seperti buku petunjuk perangkat lunak. Pengujian dilakukan dalam hal fungsionalitas seperti perangkat keras, perangkat lunak dan pengujian Blackbox. Pengujian Blackbox atau Blackbox Testing adalah tes kotak hitam dirancang untuk memverifikasi persyaratan fungsional tanpa memahami cara kerja bagian dalam program. Teknologi pengujian kotak hitam berfokus pada informasi perangkat lunak, dan menghasilkan kasus uji dengan membagi masukan serta keluaran dari program termasuk pengujian komprehensif (Destiningrum \& Adrian, 2017).

\section{Customer Evaluation}

Untuk mendapatkan aktivitas yang diinginkan menurut evaluasi pengguna atau pelanggan selama presentasi perangkat lunak dalam fase rekayasa, atau implementasi selama instalasi perangkat lunak serta fase konstruksi dan rilis, umpan balik kepada pengguna atau pelanggan.

\section{HASIL DAN PEMBAHASAN}

Pada bagian ini akan dijelaskan hasil studi dan pembahasan yang komprehensif. Hasilnya bisa disajikan dalam bentuk gambar dan spesifikasi yang detail untuk memudahkan pembaca dalam memahaminya. Bab ini berisi mengenai tahapan metode spiral yang akan diterapkan.

\section{Costumer Communication}

Pada tahap ini dilakukan komunikasi antara pengguna dengan pembuat terkait informasi mengenai sistem yang akan dibuat.

a. Pengumpulan Data

1). Observasi

Dikumpulkan data-data yang dibutuhkan dengan melakukan pengamatan secara langsung mengenai tata cara PPDB pada RA Sirojul Falah.

\section{2). Wawancara}

Melakukan wawancara langsung dengan Bpk. KH. Mulyadi, S.Pd.I selaku Ketua Yayasan Sirojul Falah, Ibu Atikah, S.Pd.I selaku Kepala Sekolah dan Ibu Syadiah Nurul Fitri selaku Staff Tata Usaha untuk memperoleh informasi yang berkaitan dengan sistem yang diteliti.

\section{3). Studi Pustaka}

Selain melalui pengamatan dan wawancara untuk mendapatkan bahan penulisan ini dari pembahasan yang berisi hal-hal yang berhubungan dengan sistem yang diteliti baik dari buku, internet maupun catatan kuliah sebagai acuan agar mendapatkan hasil capaian yang lebih optimal.

\section{b. Kebutuhan Pengguna}

Dalam aplikasi web PPDB ini terdapat dua pengguna yang saling berhubungan dalam sistem, yaitu: pengguna (calon orang tua siswa baru) dan admin. Admin dan pengguna memiliki kebutuhan yang berbeda, yaitu sebagai berikut:

1). Skenario Kebutuhan Admin

Melakukan login.

Menambahkan admin baru.

Menambahkan kegiatan.

Melakukan konfirmasi siswa baru.

Melihat kontak admin.

Melakukan logout.

2). Skenario Kebutuhan Pengguna

Melakukan pendaftaran.

Kontak admin.

\section{Planning}

Pada tahap ini akan dibuat perencanaan kebutuhan sistem, agar sistem yang dibuat dapat berjalan dengan baik sehingga diperlukan perangkat keras dan perangkat lunak untuk menganalisa kebutuhannya.

a. Spesifikasi Perangkat Keras

Saat tahap pengujian, digunakan perangkat keras untuk menjalankan aplikasi yang sudah dibangun. Adapun perangkat keras yang digunakan antara lain:

1) CPU Pentium Celeron N4020

2) RAM 4GB DDR3

3) $\mathrm{SSD} 128 \mathrm{~GB}$

4) Harddisk 500GB

5) Mouse

6) Keyboard

7) Monitor 14 inch

b. Spesifikasi Perangkat Lunak

Selain menggunakan perangkat keras, pada tahap ini dibutuhkan perangkat lunak untuk membuat dan merancang sistem serta aplikasi tersebut. Adapun perangkat lunak yang digunakan antara lain:

1) Xampp versi 7.3.11, untuk menjalankan server offline

2) Visual Studio Code, untuk membangun kode pemrograman

3) Google Chrome, sebagai browser untuk menampilkan website yang dibangun

4) Enterprise Architect, untuk membuat model UML

5) Microsoft Visio, untuk membuat ERD

6) Mysql Workbench, untuk membuat LRS

7) Balsamic Mockup, untuk membuat rancangan antarmuka (mockup) 
3. Risk Analysis

Tahapan ini digunakan untuk menganalisa kebutuhan dalam pembuatan sistem yang akan dibuat. Menu yang dirancangan yakni seperti pada Tabel 1 .

Tabel 1. Kebutuhan Fungsional

\begin{tabular}{|c|c|c|}
\hline No & $\begin{array}{c}\text { Nama } \\
\text { Kebutuhan }\end{array}$ & Deskripsi \\
\hline 1 & $\begin{array}{l}\text { Beranda } \\
\text { pengguna }\end{array}$ & Halaman setelah login \\
\hline 2 & $\begin{array}{l}\text { Formulir } \\
\text { pengguna }\end{array}$ & $\begin{array}{l}\text { Halaman pengisian } \\
\text { formulir }\end{array}$ \\
\hline 3 & Beranda admin & Halaman beranda admin \\
\hline 4 & Tambah admin & Halaman tambah admin \\
\hline 5 & $\begin{array}{l}\text { Tambah } \\
\text { kegiatan }\end{array}$ & $\begin{array}{l}\text { Halaman tambah } \\
\text { kegiatan }\end{array}$ \\
\hline 6 & $\begin{array}{l}\text { Konfirmasi } \\
\text { siswa baru }\end{array}$ & $\begin{array}{l}\text { Halaman konfirmasi } \\
\text { siswa baru }\end{array}$ \\
\hline 7 & Kontak admin & Halaman kontak admin \\
\hline
\end{tabular}

Sumber: (Puspita et al., 2021)

\section{Engineering}

Rancangan sistem dibuat dengan metode sistem berorientasi objek yaitu UML.

a. Rancangan Diagram Use Case

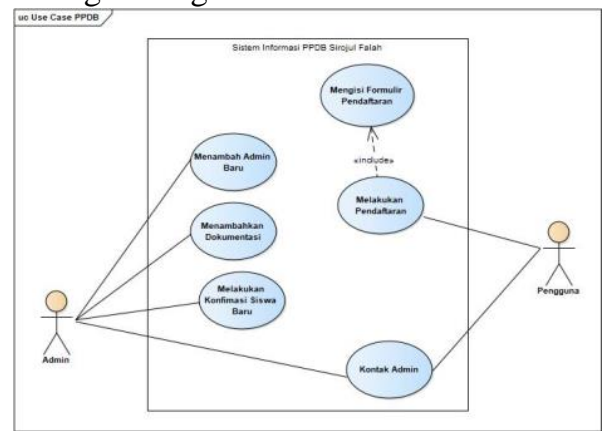

Sumber: (Puspita et al., 2021)

Gambar 2. Rancangan Diagram Use Case

b. Rancangan Activity Diagram Kontak Admin

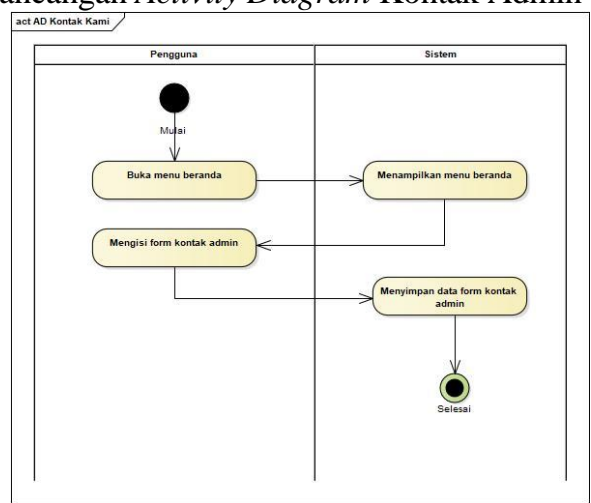

Sumber: (Puspita et al., 2021)

Gambar 3. Rancangan Activity Diagram Kontak Admin c. Rancangan Activity Diagram Admin

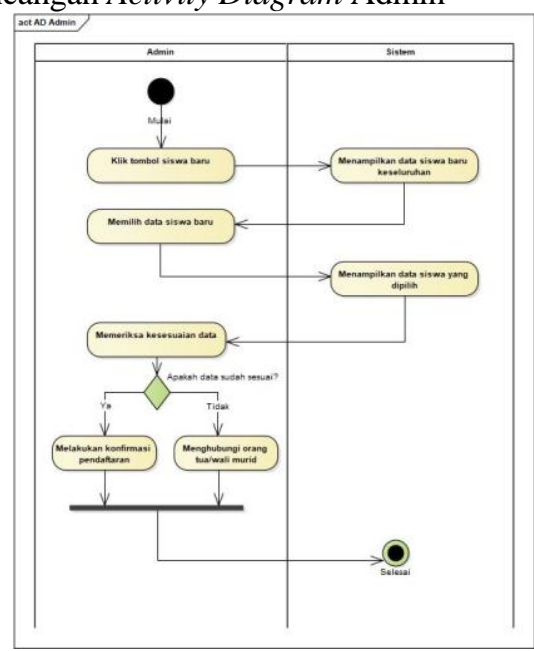

Sumber: (Puspita et al., 2021)

Gambar 4. Rancangan Activity Diagram Admin

d. Rancangan Activity Diagram Pengisian Formulir Pengguna

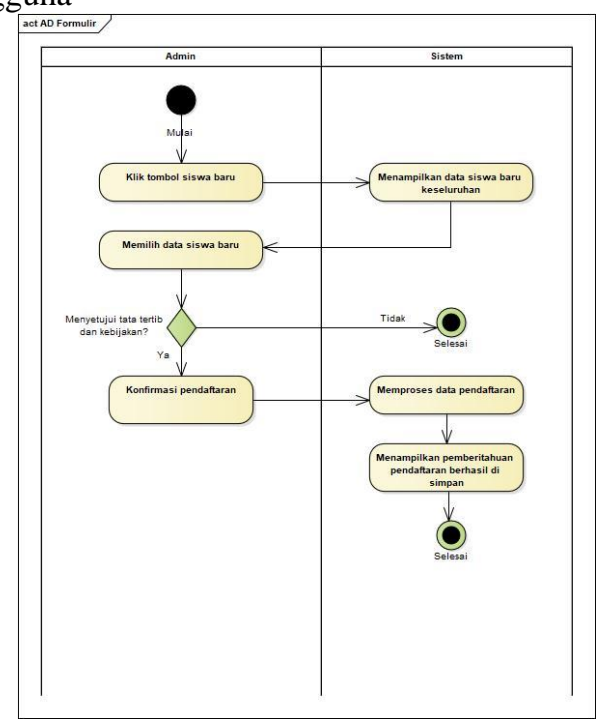

Sumber: (Puspita et al., 2021)

Gambar 5. Rancangan Activity Diagram Pengisian Formulir Pengguna

e. ERD

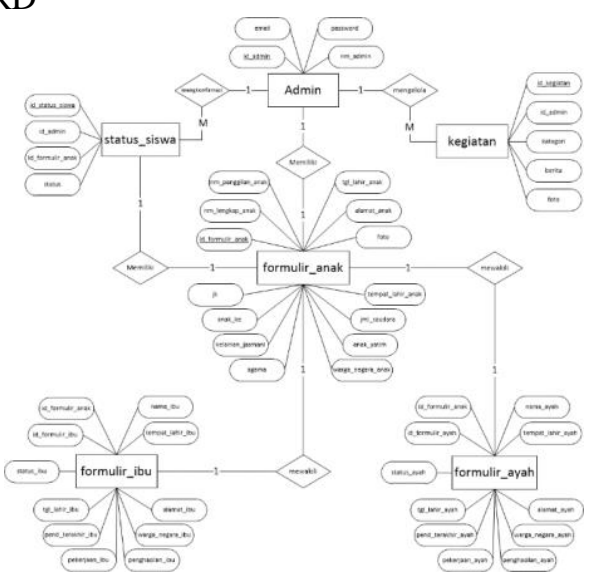

Sumber: (Puspita et al., 2021)

Gambar 6. Rancangan ERD 


\section{f. LRS}

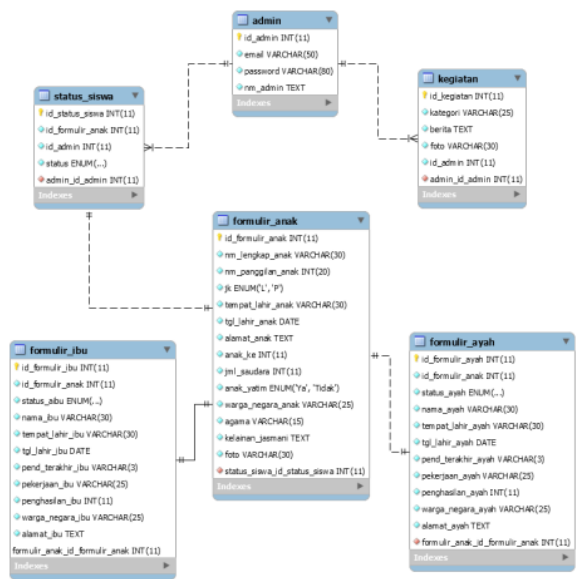

Sumber: (Puspita et al., 2021)

Gambar 7. Rancangan LRS

g. Rancangan Antarmuka

1) Rancangan Antarmuka Pengguna

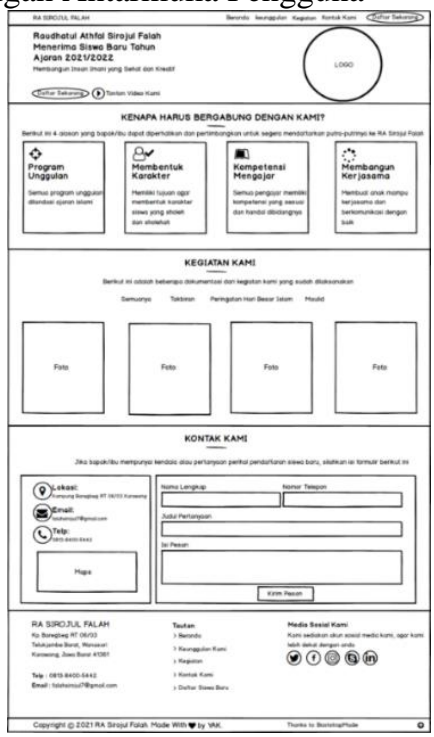

Sumber: (Puspita et al., 2021)

Gambar 8. Rancangan antarmuka beranda pengguna

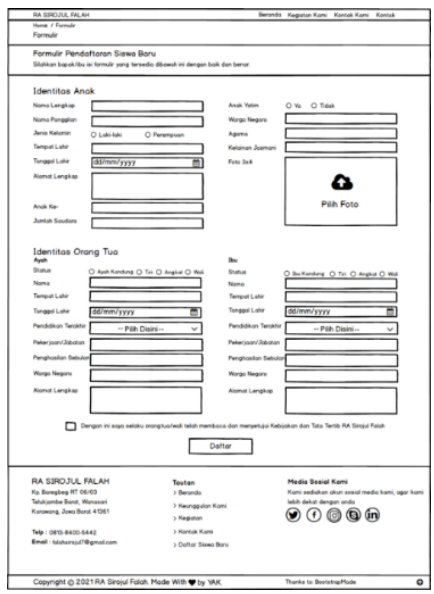

Sumber: (Puspita et al., 2021)

Gambar 9. Rancangan antarmuka formulir pendaftaran pengguna
2) Rancangan Antarmuka Admin

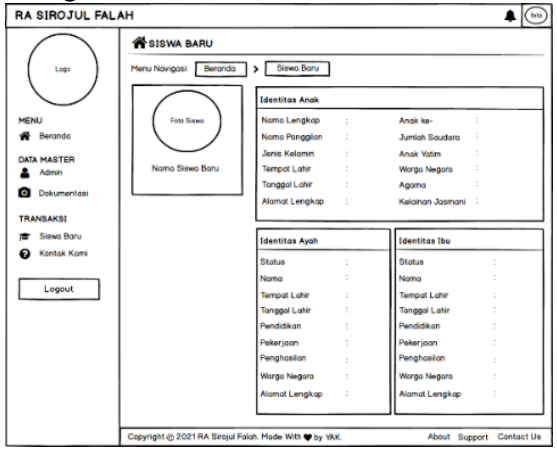

Sumber: (Puspita et al., 2021)

Gambar 10. Rancangan Antarmuka Admin

\section{Construction \& Release}

Pada tahap ini adalah tahap pembagunan sebuah aplikasi dari rancangan yang sudah dibuat sebelumnya dan dilakukan pengujian dari aplikasi tersebut.

a. Tampilan Antarmuka Admin

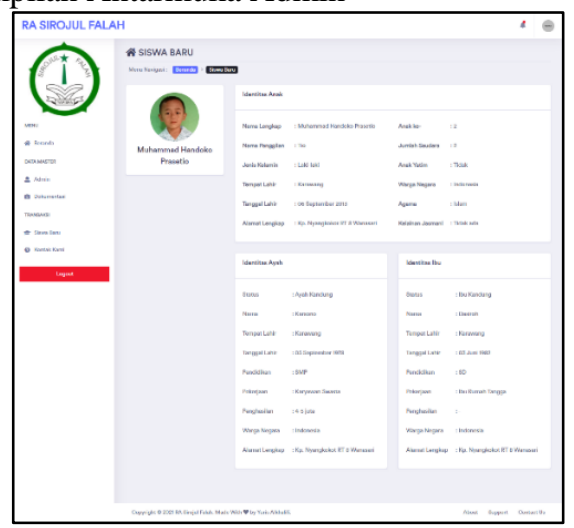

Sumber: (Puspita et al., 2021)

Gambar 11. Antarmuka Admin

b. Tampilan Antarmuka Pengguna

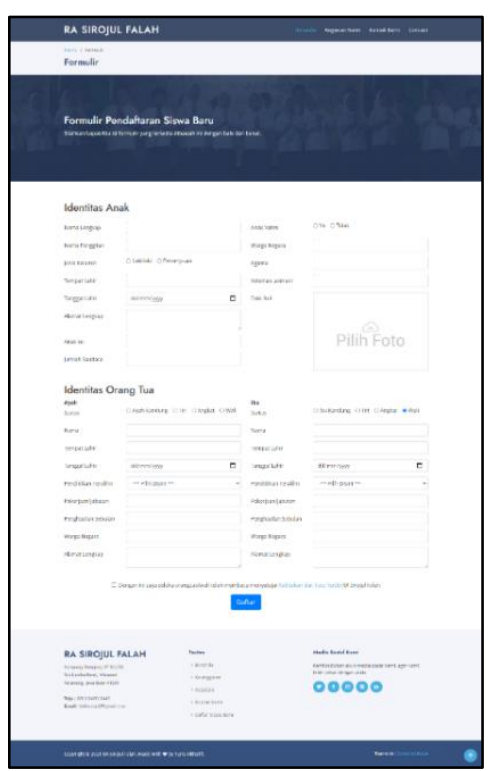

Sumber: (Puspita et al., 2021)

Gambar 12. Tampilan Antarmuka Formulir Pengguna 


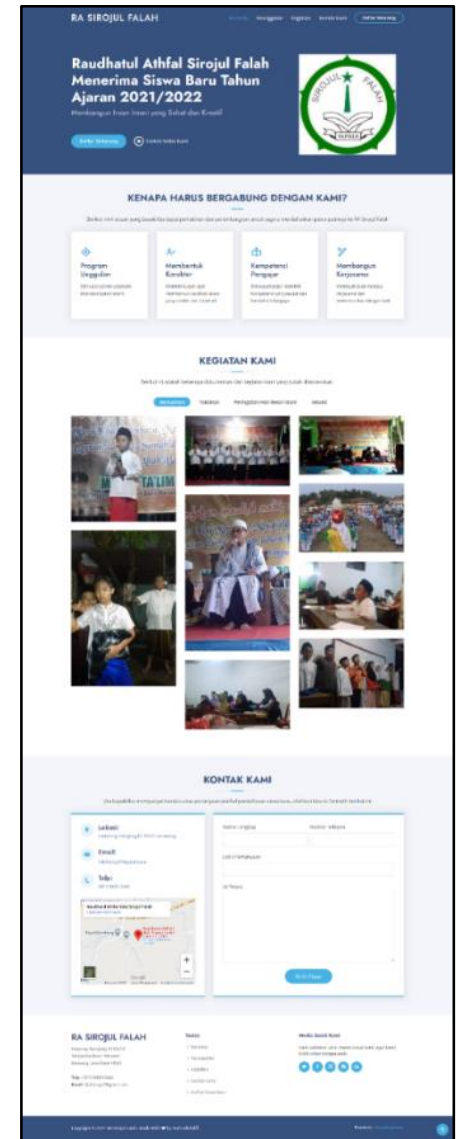

Sumber: (Puspita et al., 2021)

Gambar 13. Tampilan Antarmuka Beranda Pengguna

\section{c. Pengujian Blackbox}

Setelah aplikasi berhasil dibangun, tahapan selanjutnya adalah menguji aplikasi tersebut dengan menggunakan pendekatan pengujian blackbox. Setelah pengujian dilakukan, didapatkan hasil seperti pada Tabel 2.

Tabel 2. Pengujian Blackbox

\begin{tabular}{|c|c|c|c|}
\hline No & Nama Uji & Hasil & Kesimpulan \\
\hline 1 & $\begin{array}{l}\text { Beranda } \\
\text { pengguna }\end{array}$ & $\begin{array}{l}\text { Tampil halaman } \\
\text { beranda pengguna }\end{array}$ & Sesuai \\
\hline 2 & $\begin{array}{l}\text { Formulir } \\
\text { pengguna }\end{array}$ & $\begin{array}{l}\text { Tampil halaman } \\
\text { formulir } \\
\text { pengguna }\end{array}$ & Sesuai \\
\hline 3 & $\begin{array}{l}\text { Beranda } \\
\text { admin }\end{array}$ & $\begin{array}{l}\text { Tampil halaman } \\
\text { beranda admin }\end{array}$ & Sesuai \\
\hline 4 & $\begin{array}{l}\text { Tambah } \\
\text { admin }\end{array}$ & $\begin{array}{l}\text { Tampil halaman } \\
\text { tambah admin }\end{array}$ & Sesuai \\
\hline 5 & $\begin{array}{l}\text { Tambah } \\
\text { kegiatan }\end{array}$ & $\begin{array}{l}\text { Tampil halaman } \\
\text { tambah kegiatan }\end{array}$ & Sesuai \\
\hline 6 & $\begin{array}{l}\text { Konfirmas } \\
\text { i siswa } \\
\text { baru }\end{array}$ & $\begin{array}{l}\text { Tampil halaman } \\
\text { konfirmasi siswa } \\
\text { baru }\end{array}$ & Sesuai \\
\hline 7 & $\begin{array}{l}\text { Kontak } \\
\text { admin }\end{array}$ & $\begin{array}{l}\text { Tampil halaman } \\
\text { kontak admin }\end{array}$ & Sesuai \\
\hline
\end{tabular}

Sumber: (Puspita et al., 2021)

\section{Costumer Evaluation}

Pada metode spiral tahap ini adalah tahap terakhir yaitu evaluasi dari customer. Tahap ini dilakukan pengembangan terhadap sistem dan aplikasi yang dibuat sesuai dengan keperluan \& kebutuhan customer. Jika ada pengembangan dari sistem maupun aplikasinya, maka dilakukan kembali pengulangan dari tahap komunikasi dengan customer.

\section{KESIMPULAN}

Berdasarkan hasil penelitian, sistem informasi berupa website berhasil dibangun menggunakan bahasa pemrograman PHP, MySQL, framework codeigniter dan library bootstrap serta didukung dengan rancangan antarmuka, ERD, LRS dan UML sehingga aplikasi dapat digunakan dan diterapkan pada RA Sirojul Falah. Dengan adanya sistem informasi ini, diharapkan dapat membantu panitia PPDB untuk mengelola data siswa baru dengan mudah praktis dan cepat.

\section{REFERENSI}

Abdi, M., \& Purwoko, B. (2017). Studi Kepustakaan Mengenai Landasan Teori Dan Praktik Konseling Expressive Writing Library. Jurnal BK UNESA, 1, 1-8.

Ahsanulkhaq, M. (2019). Membentuk Karakter Religius Peserta Didik Melalui Metode Pembiasaan. Jurnal Prakarsa Paedagogia, 2(1), 21-33.

Alkhalifi, Y., Gata, W., Prasetyo, A., \& Budiawan, I. (2020). Analisis Sentimen Penghapusan Ujian Nasional pada Twitter Menggunakan Support Vector Machine dan Naïve Bayes berbasis Particle Swarm Optimization. CoreIT, 6(2).

Aprilyani, F., \& Syarifuddin. (2016). Sistem Informasi Penerimaan Peserta Didik Baru (Ppdb) Berbasis Web Pada Sma Budi Mulia Tangerang. Jurnal Sisfokom (Sistem Informasi Dan Komputer), 1, 47-52.

Basri, H., Alfarizi, S., Mulyawan, A. R., Wiguna, A., \& Habiba, I. (2019). Perancangan Sistem Informasi Booking Perekaman E-Ktp (Si Mbok) Berbasis Web. Jurnal Pilar Nusa Mandiri, 15(1), 69-76. https://doi.org/10.33480/pilar.v15i1.103

Cahyati, Y., \& Murti, H. (2018). Sistem E-Surat Pada Government Resource Management System Provinsi Jawa Tengah Berbasis Framework Codeigniter. Universitas Stikubank, 978-979.

Christian, A., Hesinto, S., \& Agustina, A. (2018). Rancang Bangun Website Sekolah Dengan Menggunakan Framework Bootstrap ( Studi Kasus SMP Negeri 6 Prabumulih ). Jurnal Sisfokom (Sistem Informasi Dan Komputer), $7(1)$, 22. https://doi.org/10.32736/sisfokom.v7i1.278

Destiningrum, M., \& Adrian, Q. J. (2017). Sistem Informasi Penjadwalan Dokter Berbassis Web Dengan Menggunakan Framework Codeigniter (Studi Kasus: Rumah Sakit Yukum Medical Centre). Jurnal Teknoinfo, 11(2), 30. https://doi.org/10.33365/jti.v11i2.24 
Effendy, A. A., \& Sunarsi, D. (2020). Persepsi Mahasiswa Terhadap Kemampuan Dalam Mendirikan UMKM Dan Efektivitas Promosi Melalui Online Di Kota Tangerang Selatan. JURNAL ILMIAH MEA (Manajemen, Ekonomi, Dan Akuntansi), 4(3), 702-714. https://journal.stiemb.ac.id/index.php/mea/artic le/download/571/248

Ermawati, E. (2019). Algoritma Klasifikasi C4.5 Berbasis Particle Swarm Optimization Untuk Prediksi Penerima Bantuan Pangan Non Tunai. Sistemasi, $8(3), \quad 513$. https://doi.org/10.32520/stmsi.v8i3.576

Haryati, S. (2017). PENDIDIKAN KARAKTER DALAM KURIKULUM 2013 Oleh: Sri Haryati (FKIP-UTM). Pendidikan Karakter Dalam Kurikulum 2013, 19(2), 259-268.

Hasan, Nur, F., \& Nurlelah, E. (2020). Perancangan Sistem Monitoring Kinerja Staf Berbasis Web Studi Kasus Bsi Entrepreneur Center. Pembelajaran Olah Vokal Di Prodi Seni Pertunjukan Universitas Tanjungpura Pontianak, 28(2), 1-43. http://journals.sagepub.com/doi/10.1177/11207 00020921110\%0Ahttps://doi.org/10.1016/j.reu ma.2018.06.001\%0Ahttps://doi.org/10.1016/j.a rth.2018.03.044\%0Ahttps://reader.elsevier.com /reader/sd/pii/S1063458420300078?token $=$ C03 9B8B13922A2079230DC9AF11A333E295FC D8

Hasbullah, S. A. (2019). Evaluasi Kebijakan Sistem Zonasi dalam PPDB di Tingkat Sekolah Menengah Pertama Negeri di Kabupaten Pamekasan. Jurnal Reformasi, 9(2), 112-122.

Hendini, A. (2016). PEMODELAN UML SISTEM INFORMASI MONITORING PENJUALAN DAN STOK BARANG (STUDI KASUS DISTRO ZHEZHA PONTIANAK). IV(2), 107-116. https://doi.org/https://doi.org/10.31294/jki.v4i2 .1262.g1027

Josi, A. (2017). Penerapan Metode Prototyping Dalam Membangun Website Desa (Studi Kasus Desa Sugihan Kecamatan Rambang). Jti, 9(1), 50-57.

Mesiono. (2017). Manajemen Pendidikan Raudhatul Athfal (RA) Pengantar Teori dan Praktik (1st ed.). Perdana Publishing.

Najamudin, N., Bagye, W., \& Ashari, M. (2019). Aplikasi Penerimaan Peserta Didik Baru Berbasis Web Pada Smk Negeri 2 Kuripan. Jurnal Manajemen Informatika Dan Sistem Informasi, $2(2)$, https://doi.org/10.36595/misi.v2i2.100

Puspita, K., Alkhalifi, Y., \& Basri, H. (2021). Rancang Bangun Sistem Informasi Penerimaan Peserta Didik Baru Berbasis Website Dengan Metode Spiral (Vol. 23, Issue 1).

Ramdhan, N. A., \& Wahyudi, D. (2019). Sistem Informasi Penerimaan Peserta Didik Baru (PPDB) Berbasis WEB Di SMP Negri 1 Wanasari Brebes. Jurnal Ilmiah Intech:
Information Technology Journal of UMUS, 1(01), 56-65. https://doi.org/10.46772/intech.v1i01.38

Ratnawati, Siwi, R. D., \& Faqih, H. (2018). Pendekatan Rapid Application Development Dalam Merancang Program Administrasi Klinik (Studi Kasus: Klinik Anugerah Sehat). 10(3), 62-67.

Sentosa, I. M. A. (2017). Perancangan Sistem Pendukung Keputusan Pemilihan Sekolah PAUD Menggunakan Metode Smart. Konferensi Nasional Sistem \& Informatika 2017, 446-451.

Suherni, S., Rubiati, N., \& Khumaini, H. (2017). APLIKASI PENDAFTARAN DAN PENERIMAAN SISWA BARU DI SMK NEGERI 1 RUPAT BERBASIS WEB. Jurnal Informatika, Manajemen Dan Komputer, Vol. 9 No. 2, Desember 2017, 9(2), 15-24. http://www.ejournal.stmikdumai.ac.id/index.ph p/path/article/view/99/38\#

Utomo, A. N., \& Alfaridzi, M. (2018). Perancangan Sistem Informasi Pada Percetakan CV Citra Kencana Jakarta Timur Berbasis Web. Jurnal Rekayasa Informasi, 7(1), 43-47.

Wahyuni, S., \& Cahyani, N. (2020). Penerapan Model Spiral Dalam Pengembangan Sistem Informasi Penjadwalan Produksi Berbasis Website (Studi Kasus: PT. Dinar Makmur Cikarang). Informatics and Digital Expert (INDEX), 2(1), 1-6. https://doi.org/10.36423/ide.v2i1.425

\section{PROFIL PENULIS}

Kartika Puspita merupakan mahasiswa aktif di Universitas Bina Sarana Informatika (UBSI). Saat ini sedang menempuh pendidikan D3 pada program studi Sistem Informasi.

Yuris Alkhalifi merupakan dosen aktif di Universitas Bina Sarana Informatika (UBSI). Bidang penelitian yang didalami adalah Sistem Informasi dan Ilmu Komputer. Menamatkan pendidikan D3 program studi Sistem Informasi di UBSI, pendidikan S1 program studi Sistem Informasi di STMIK Nusa Mandiri dan pendidikan S2 program studi Ilmu Komputer pada STMIK Nusa Mandiri.

Hasan Basri lahir di Karawang pada tanggal 20 oktober 1993. Saat ini menjalani profesi sebagai dosen tetap di Universitas Bina Sarana Informatika Kampus Kabupaten Karawang. Profesi sebagai dosen dikembangkan dengan mengikuti berbagai pelatihan sehingga sekarang mendapatkan beberapa sertifikat sertifikasi programmer, Sertifikasi Asesor Kompetensi Programmer. Selain itu juga aktif sebagai reviewer jurnal nasional terkareditasi sinta 3 pada OJS SISTEMASI dan Reviewer OJS SIMPATIK. 